\title{
The 3 R's for Platelet-Rich Fibrin: A "Super" Tri-Dimensional Biomaterial for Contemporary Naturally-Guided Oro-Maxillo-Facial Soft and Hard Tissue Repair, Reconstruction and Regeneration
}

\author{
Consuelo C. Zumarán ${ }^{1}$, Marcelo V. Parra ${ }^{2}$, Sergio A. Olate ${ }^{2}$, Eduardo G. Fernández ${ }^{3,4}$, \\ Francisco T. Muñoz ${ }^{1,5}$ and Ziyad S. Haidar 1,5,6,7,* (D) \\ 1 BioMAT'X, Facultad de Odontología, Universidad de los Andes, Santiago 7550000, Chile; \\ czumaran@uandes.cl (C.C.Z.); fmunoz.thomson@gmail.com (F.T.M.) \\ 2 CEMyQ, Facultad de Odontología, Universidad de La Frontera, Temuco 4780000, Chile; \\ marcelo.parra@ufrontera.cl (M.V.P.); sergio.olate@ufrontera.cl (S.A.O.) \\ 3 Departamento de Odontología Restauradora, Facultad de Odontología, Universidad de Chile, \\ Santiago 8320000, Chile; edofdez@yahoo.com \\ 4 Instituto de Ciencias Biomédicas, Universidad Autónoma de Chile, Santiago 7500912, Chile \\ 5 Programa de Especialización en Cirugía Bucal y Maxilofacial, Facultad de Odontología, \\ Universidad de los Andes, Santiago 7550000, Chile \\ 6 Programa de Doctorado (BioMedicina), Facultad de Medicina, Universidad de los Andes, \\ Santiago 7550000, Chile \\ 7 Centro de Investigación e Innovación Biomédica (CIIB), Facultad de Medicina, Universidad de los Andes, \\ Santiago 7550000, Chile \\ * Correspondence: zhaidar@uandes.cl; Tel.: +56-2-2618-1372; Fax: +56-2-2214-9468
}

Received: 5 July 2018; Accepted: 23 July 2018; Published: 26 July 2018

\begin{abstract}
Platelet-Rich fibrin (PRF) is a three-dimensional (3-D) autogenous biomaterial obtained via simple and rapid centrifugation from the patient's whole blood samples, without including anti-coagulants, bovine thrombin, additives, or any gelifying agents. At the moment, it is safe to say that in oral and maxillofacial surgery, PRFs (particularly, the pure platelet-rich fibrin or P-PRF and leukocyte and platelet-rich fibrin or L-PRF sub-families) are receiving the most attention, essentially because of their simplicity, cost-effectiveness, and user-friendliness/malleability; they are a fairly new "revolutionary" step in second-generation therapies based on platelet concentration, indeed. Yet, the clinical effectiveness of such surgical adjuvants or regenerative platelet concentrate-based preparations continues to be highly debatable, primarily as a result of preparation protocol variability, limited evidence-based clinical literature, and/or poor understanding of bio-components and clinico-mechanical properties. To provide a practical update on the application of PRFs during oral surgery procedures, this critical review focuses on evidence obtained from human randomized and controlled clinical trials only. The aim is to serve the reader with current information on the clinical potential, limitations, challenges, and prospects of PRFs. Accordingly, reports often associate autologous PRFs with early bone formation and maturation; accelerated soft-tissue healing; and reduced post-surgical edema, pain, and discomfort. An advanced and original tool in regenerative dentistry, PRFs present a strong alternative and presumably cost-effective biomaterial for oro-maxillo-facial tissue (soft and hard) repair and regeneration. Yet, preparation protocols continue to be a source of confusion, thereby requiring revision and standardization. Moreover, to increase the validity, comprehension, and therapeutic potential of the reported findings or observations, a decent analysis of the mechanico-rheological properties, bio-components, and their bioactive function is eagerly needed and awaited; afterwards, the field can progress toward a brand-new era of "super" oro-dental biomaterials and bioscaffolds for use in oral and maxillofacial tissue repair and regeneration, and beyond.
\end{abstract}


Keywords: tissue engineering; regeneration; leukocyte; platelet; fibrin; growth factors; dentistry; oral surgery; periodontology; osteogenesis; grafts

\section{Introduction}

Even though significant improvements in restoration and/or replacement approaches and supplies have been accomplished over the last decades, the repair and regeneration of defects remains a challenge [1]. Indeed, current clinical approaches that have been used to reconstruct and heal complex defects, including different multi-disciplinary methods of bone grafting, such as autologous bone grafts, distraction osteogenesis, allografts, bone-graft substitutes, and/or guided bone regeneration, are deemed restricted on a daily basis. This is often multi-factorial; whether due to the limited self-renewal capacity of the defect and/or the limited donor supply, increased morbidity, risk of antigenicity, and foreign body reactions associated with the grafts used. While several oro-dental soft and hard tissues have been regenerated using mesenchymal stem cells (oro-dental sources mainly), the translation of novel biomaterials to the clinic has been slow. This is attributed to a lack of scientific knowledge and ethical considerations. Overall, operative-associated time and cost contribute as well. Hence, the field of dentistry (in general, and oral surgery specialties, in particular) is anticipated to significantly transform in the next two to three decades via the introduction of innovative tissue engineering and/or tissue-engineered bio-products. This boom will include various oro-dental soft and hard tissues including enamel, dentin, alveolar jaw bone, periodontium, oral and buccal mucosa, as well as the salivary glands. Thereby, the art and science of oro-maxillo-facial reconstruction is of great interest for contemporary oral and maxillofacial surgeons as part of the search for better bioengineering strategies and biomaterials, which is a core driver for bio-dental research today [2]. Platelet concentrates are a fine example.

In simple words, the 'product' resulting from the centrifugation of whole blood samples are autologous blood extracts, so-called platelet concentrates (Figure 1). In clinically-usable preparations (surgical adjuvants), the preparation procedure may enhance, accelerate, and promote tissue (soft and hard) wound healing and regeneration due to its potential to allow the gathering and concentration of platelets and other therapeutic blood constituents (fibrinogen/fibrin, growth factors, leukocytes, and circulating cells) [3]. Currently, their overall effectiveness remains debated, despite promising clinical observations. The main reasons are: contradictory clinical outcomes, insufficient high-quality evidence-based literature, and poor identification of the characteristics of the end-products (and preparation protocols) used in research studies; along with-until recently-a lack of proper nomenclature to typify these concentrates [4]. In fact, in 2009, the first "classification" consensus [5] was published, categorizing four particular platelet concentrate sub-families relying on differences in biological components (fibrin and cell), properties (gelification), and possible applications: pure platelet-rich plasma (P-PRP), leukocyte and platelet-rich plasma (L-PRP), pure platelet-rich fibrin (P-PRF), and leukocyte and platelet-rich fibrin (L-PRF) [5]. Nowadays, when compared to the PRPs, it can be stated that in oral and maxillofacial surgery, the PRFs (P-PRF and L-PRF sub-families; not including red blood cells within) [4-6] are receiving the highest consideration and hype, which is mainly due to their preparation simplicity and rapidness, user-friendliness/malleability, and likely cost-effectiveness.

PRF and L-PRF are second-generation autologous platelet concentrates of whole venous blood [4,6]. A fibrin gel that is polymerized slowly and strongly (Figure 2) abundant in growth factors, platelets, leukocytes (almost half of the initial blood harvest), and lymphocytes is collected, following simple and rapid ( 10 $\mathrm{min}$ ) centrifugation (please note that preparation protocols vary) of blood, in vacutainer tubes, without anti-coagulant. The gathered clot (or biomaterial) is stable, resilient, strong, adhesive, and malleable. It can be cut or adapted into different anatomical defects and applications: bended with bone grafting material, applied as filling material in a direct way, or compacted into a strong fibrin 
membrane. Alongside this established clinical ease of use and handling, the biochemical composition of the PRF by-products provides it with attractive hemostatic, angiogenic, osteogenic, anti-inflammatory, anti-microbial, pain-inhibitory, and wound-healing characteristics [3,7,8]. This critical review aims to provide the clinical reader with an up-to-date evidence-based presentation on the evaluation of PRFs' (mainly, P-PRF and L-PRF) use and application for oro-maxillo-facial tissue regeneration, from high-quality randomized and controlled clinical trials. Thus, in vitro, in vivo, and case report studies were intentionally excluded from analysis.

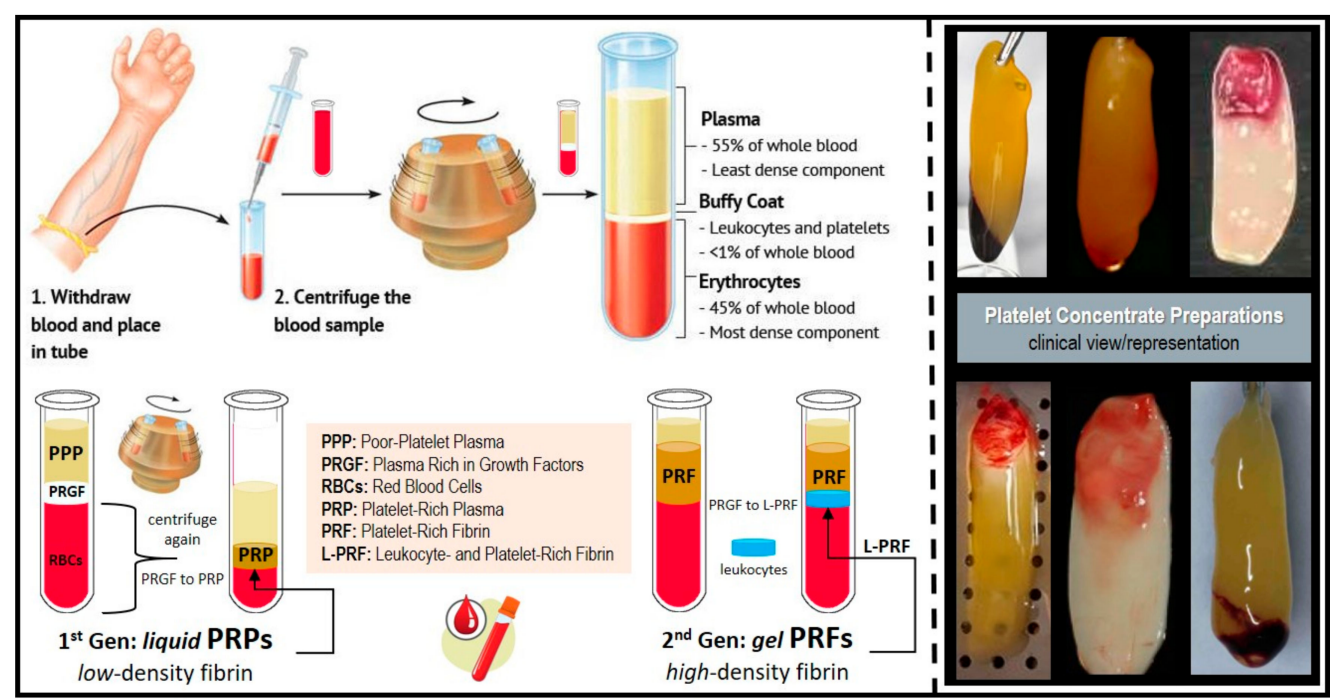

Figure 1. Platelet concentrates' clinical preparation, types/classes, and clinical illustration/presentation of several platelet-rich fibrin (PRF) and leukocyte and platelet-rich fibrin (L-PRF) preparations (membranes).

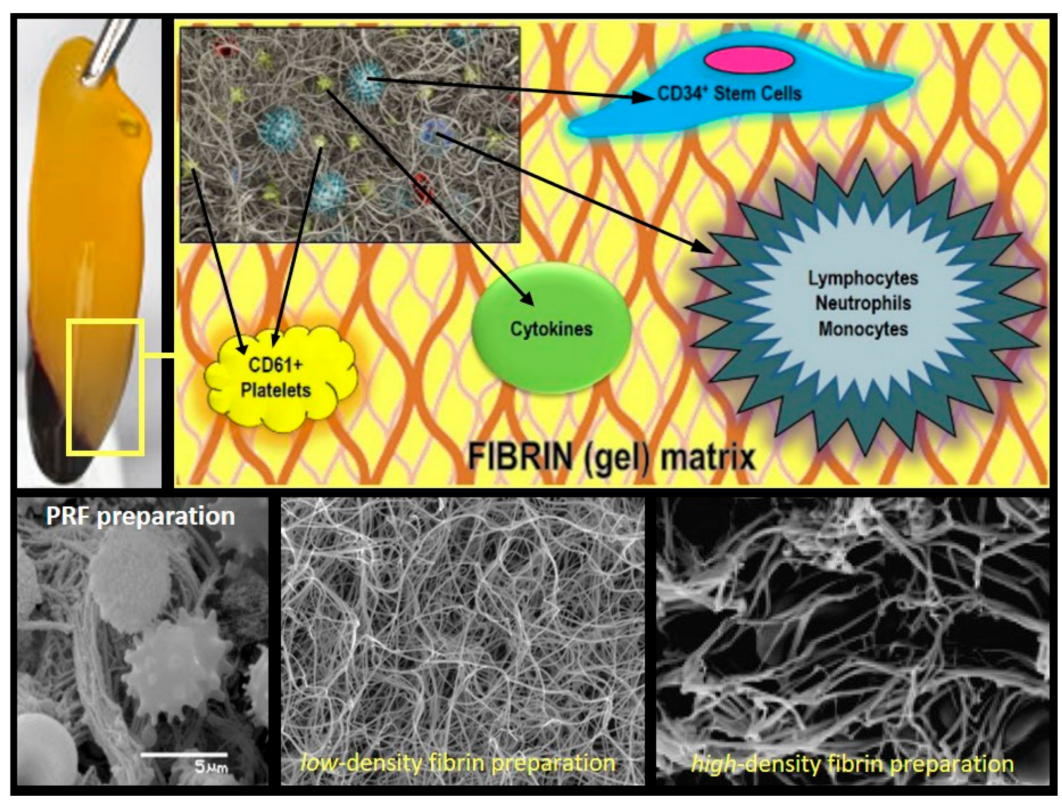

Figure 2. PRF Composition/Architecture Illustration. Schematic representation of PRF bio-components and SEM (scanning electron microscope) micrographs of the PRF membranes displaying its polymerized interconnected fibrin network and large living cell population content. 


\section{Materials and Methods}

A systematic and structured literature search (Figure 3) conducted on PUBMED (January 2008-May 2018) including the MeSH (Medical Subject Headings) terms "platelet-rich fibrin" and "platelet-rich plasma" with the search strategy established as: "platelet-rich fibrin" [All Fields] NOT "platelet-rich plasma" [All Fields]. The filters that were used to limit the results were: Seniority (published 10 years ago: up to May 2018), Language (English), Availability (Full-text), and Species (Human). Inclusion criteria were: (a) randomized clinical trials (RCTs) using (b) Choukroun's PRFs in (c) oro-maxillo-facial procedures. The initial search resulted in 191 articles, 21 of which met the inclusion criteria. Five articles were then excluded due to (exclusion criteria) quality, availability, and/or lack of randomization. Due to the high heterogeneity in the analyzed literature, the results are presented and discussed in a narrative format.

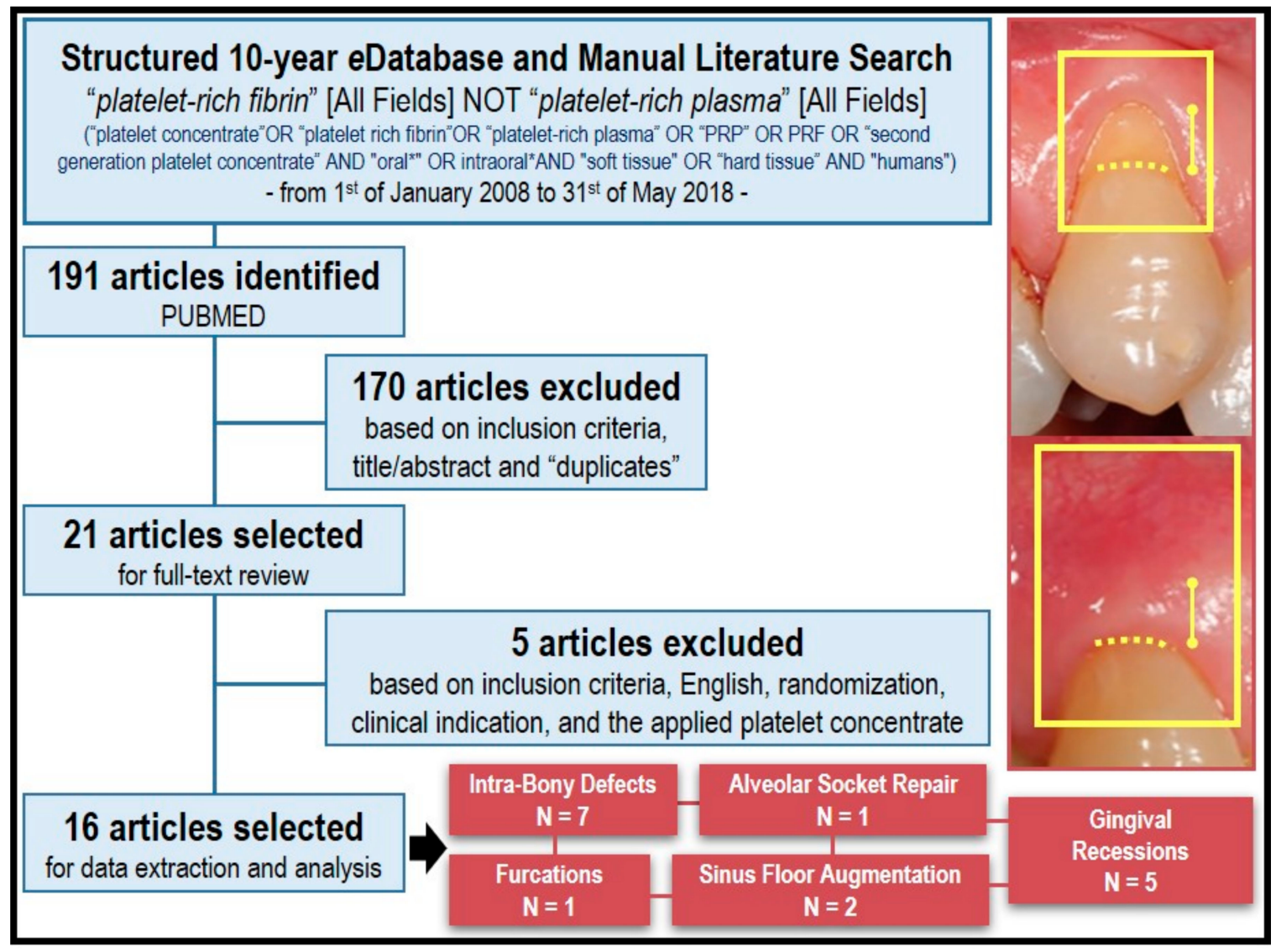

Figure 3. Flow chart of literature search strategy, hits, and included studies for data extraction and analysis. A clinical example illustrating the benefits of PRF application in treating gingival recession is displayed.

\section{Results and Discussion}

The initial search yielded 191 articles in PUBMED. After title, abstract, and text screening, 21 articles met the initial inclusion criteria. Google Scholar and hand searching the bibliography section of select reviews yielded similar results. After full-text analysis, five articles were excluded due to meeting the pre-established exclusion criteria, resulting in 16 studies (Table 1) that were opted for data extraction and analysis. 
Table 1. Summary of clinical literature (randomized clinical trials, or RCTs) on L-PRF use in oral and maxillofacial Surgery. IBD: intra-bony defects.

\begin{tabular}{|c|c|c|c|c|c|}
\hline Application & No. Patients/Defects & Groups & Follow-Up (Months) & Main Finding(s) & Reference \\
\hline IBD & $32 / 32$ & $\begin{array}{l}\text { (1) PRF + open flap surgery } \\
\text { (2) Open flap surgery }\end{array}$ & 9 & $\begin{array}{l}\text { All sites healed uneventfully. Probing depth (PD) reduction, } \\
\text { average clinical attachment (CAL) gain, defect fill, percentage } \\
\text { defect fill and post-treatment gingival margin stability were } \\
\text { significantly greater in the PRF-treated group. }(P<0.05) \text {. }\end{array}$ & [9] \\
\hline IBD & $15 / 30$ & $\begin{array}{l}\text { (1) PRF + open flap surgery } \\
\text { (2) Open flap surgery }\end{array}$ & 12 & $\begin{array}{l}\text { All sites healed uneventfully. PD reduction, CAL gain, } \\
\text { radiographic IBD depth reduction, and post-treatment gingival } \\
\text { margin stability were significantly higher in the PRF group. } \\
\text { Statistically significant higher patient acceptance and healing } \\
\text { index in PRF vs. control. }\end{array}$ & [10] \\
\hline IBD & $35 / 56$ & $\begin{array}{l}\text { (1) PRF + open flap surgery } \\
\text { (2) Open flap surgery }\end{array}$ & 9 & $\begin{array}{l}\text { All sites healed uneventfully. PD reduction, CAL gain, } \\
\text { radiographic IBD defect fill were significantly higher in the PRF } \\
\text { group. Gingival Margin Stability (GMS) was higher in the } \\
\text { PRF group. }\end{array}$ & [11] \\
\hline IBD & $17 / 34$ & $\begin{array}{l}\text { (1) PRF + Bio-Oss }{ }^{\circledR} \\
\text { (2) PRF }\end{array}$ & 6 & $\begin{array}{l}\text { All sites healed uneventfully. Both groups showed significant } \\
\text { PD reduction, CAL gain, and IBD fill. Intergroup differences } \\
\text { were also significant and favored the PRF/Bio-Oss group. }\end{array}$ & [12] \\
\hline IBD & $10 / 20$ & $\begin{array}{l}\text { (1) PRF + DFDBA } \\
\text { (2) DFDBA (demineralized-freeze dried } \\
\text { bone allograft) }\end{array}$ & 6 & $\begin{array}{l}\text { Both groups experienced significant PD reduction, CAL gain, } \\
\text { IBD fill, and IBD resolution. Intergroup differences were } \\
\text { statistically significant only for PD reduction and CAL gain, } \\
\text { favoring the PRF/DFDBA group. }\end{array}$ & [13] \\
\hline IBD & $21 / 21$ & $\begin{array}{l}\text { (1) PRF + inorganic bovine bone mineral } \\
\text { (2) Anorganic bovine bone mineral }\end{array}$ & 6 & $\begin{array}{l}\text { All of the sites healed uneventfully with no clinically detectable } \\
\text { or subjectively reported side effects. Both treatment groups } \\
\text { showed significant improvements compared to baseline in } \\
\text { terms of vertical bone gain, defect fill, and defect angle at six } \\
\text { months after treatment }(P<0.05) \text {. Addition of PRF to inorganic } \\
\text { bovine bone mineral (ABBM: Anorganic bovine bone mineral) } \\
\text { may lead to the enhancement of clinical attachment level gain. }\end{array}$ & [14] \\
\hline IBD & $16 / 32$ & $\begin{array}{l}\text { (1) Resorbable collagen membrane + PRF } \\
\text { (2) Guidance tissue regeneration }\end{array}$ & 9 & $\begin{array}{l}\text { Test group showed a statistically significant improvement for } \\
\text { probing depth }(P=0.002) \text {, clinical attachment level }(P=0.001) \text {, } \\
\text { and radiographic defect depth }(P<0.001) \text { after nine months as } \\
\text { compared with the control sites. The adjunctive use of PRF in } \\
\text { combination with barrier membrane is more effective in the } \\
\text { treatment of intrabony defects in chronic periodontitis as } \\
\text { compared with barrier membrane alone. }\end{array}$ & [15] \\
\hline $\begin{array}{l}\text { PFD (Periodontal } \\
\text { Furcation Defect) }\end{array}$ & $18 / 38$ & $\begin{array}{l}\text { (1) PRF + open flap surgery } \\
\text { (2) Open flap surgery }\end{array}$ & 9 & $\begin{array}{l}\text { All sites healed uneventfully. No significant visual differences } \\
\text { between groups were noticed. Complete clinical closure was } \\
\text { achieved in } 66.7 \% \text { of the defects in the PRF group. Within } \\
\text { residual furcation defects, } 5 / 6 \text { were reduced from grade II to } \\
\text { grade I, and one defect remained grade II. Significantly greater } \\
\text { PD reduction, CAL gain, and defect fill was noticed in the } \\
\text { PRF-treated group vs. control. }\end{array}$ & [16] \\
\hline
\end{tabular}


Table 1. Cont

\begin{tabular}{|c|c|c|c|c|c|}
\hline Application & No. Patients/Defects & Groups & Follow-Up (Months) & Main Finding(s) & Reference \\
\hline Gingival Recession & $15 / 30$ & $\begin{array}{l}\text { (1) PRF }+ \text { coronally-advanced flaps (CAF) } \\
\text { (2) CAF }\end{array}$ & 6 & $\begin{array}{l}\text { Both groups experienced statistically significant recession } \\
\text { depth (RD) reduction, CAL gain, and keratinized tissue width } \\
\text { (KTW) increase at all time intervals }(P<0.05) \text {. Intergroup } \\
\text { differences were statistically significant and favored the PRF } \\
\text { group. Mean percentage of root coverage for the test and } \\
\text { control groups were } 100 \% \text { and } 68.44 \% \text {, respectively. Differences } \\
\text { between groups were statistically significant and favored the } \\
\text { PRF group. }\end{array}$ & [17] \\
\hline Gingival Recession & $20 / 67$ & $\begin{array}{l}\text { (1) PRF + CAF } \\
\text { (2) CAF }\end{array}$ & 6 & $\begin{array}{l}\text { With the exception of CAL gain and gingival tissue thickness } \\
\text { (GTH) increase, the addition of PRF to CAF failed to produce } \\
\text { significant additional clinical benefits (vs. CAF-alone). } \\
\text { Percentage root coverage, full root coverage, GMS, and } \\
\text { recession width (RW) reduction were significantly higher in the } \\
\text { CAF controls than the PRF-treated sites after six months. }\end{array}$ & [18] \\
\hline Gingival Recession & $20 / 40$ & $\begin{array}{l}\text { (1) PRF + CAF } \\
\text { (2) } \mathrm{EMD}+\mathrm{CAF}\end{array}$ & 12 & $\begin{array}{l}\text { Both groups experienced statistically significant RD reduction, } \\
\text { PD reduction, and KTW increase. Intergroup differences were } \\
\text { significant only for KTW increase and favored the enamel } \\
\text { matrix derivate (EMD) group. Mean root coverage was } 70.5 \pm \\
11.76 \% \text { in the EMD group, and } 72.1 \pm 9.55 \% \text { in the PRF group. } \\
\text { Complete root coverage was achieved in } 60 \% \text { of the EMD sites } \\
\text { and } 65 \% \text { of the PRF sited. No intergroup comparison was } \\
\text { carried out. The healing index of the PRF group after the first } \\
\text { week was significantly superior to that of EMD. Non-significant } \\
\text { differences between groups were found after two weeks } \\
\text { post-surgery. Three patients of the EMD group and one of the } \\
\text { PRF group experienced severe pain. All of the patients in the } \\
\text { EMD group reported greater discomfort. Analysis of the first } \\
\text { five days post-surgery revealed statistically significant } \\
\text { differences between both groups favoring PRF (less pain). }\end{array}$ & [19] \\
\hline Gingival Recession & $22 / 44$ & $\begin{array}{c}\text { (1) PRF + CAF } \\
\text { (2) } \mathrm{SCTG} \text { (subepithelial connective tissue } \\
\text { graft) + CAF }\end{array}$ & 6 & $\begin{array}{l}\text { Both groups experienced a statistically significant decrease in } \\
\text { RD (Gingival recession depth), RW (Gingival recession width), } \\
\text { and RA (Gingival Recession Area), plus an increase in CAL } \\
\text { (Clinical Attachment Level) gain, KTW (Keratinized Tissue } \\
\text { Width), and GT (Gingival Thickness). Intergroup differences } \\
\text { were non-significant. Higher yet non-significant gingival } \\
\text { margin stability was reported for the PRF group. Percentage of } \\
\text { root coverage and complete root coverage were } 92.7 \% \text { and } \\
72.7 \% \text { in the test group and } 94.2 \% \text { and } 77.3 \% \text { in the control } \\
\text { group. No statistical significant differences between both } \\
\text { groups were found (P }>0.05) \text {. All of the sites healed } \\
\text { uneventfully; however, the control group reported } \\
\text { complications (i.e., pain) related to the palate donor site. }\end{array}$ & [20] \\
\hline
\end{tabular}


Table 1. Cont.

\begin{tabular}{|c|c|c|c|c|c|}
\hline Application & No. Patients/Defects & Groups & Follow-Up (Months) & Main Finding(s) & Reference \\
\hline Gingival Recession & $15 / 30$ & $\begin{array}{c}\text { (1) PRF + CAF } \\
\text { (2) Connective tissue grafts (CTG) + CAF }\end{array}$ & 6 & $\begin{array}{l}\text { Both groups experienced a significant CAL gain, RD reduction, } \\
\text { and GMS. Intergroup differences were non-significant. Both } \\
\text { groups experienced a statistically significant increase in KTW. } \\
\text { Intergroup differences were statistically significant and favored } \\
\text { the CTG group. Mean root coverage was } 88.68 \pm 10.65 \% \text { for the } \\
\text { PRF group and } 91.96 \pm 15.46 \% \text { for the control group. Complete } \\
\text { root coverage was achieved in } 75.85 \% \text { of cases in the PRF group } \\
\text { and } 79.56 \% \text { of cases in the control group. Intergroup } \\
\text { differences were non-significant. Healing index values of the } \\
\text { PRF group during the first two weeks were statistically } \\
\text { superior to those of the CTG control. One patient from the PRF } \\
\text { group and seven from the CTG group experienced severe pain. } \\
\text { Also, all of the patients in the control group reported some } \\
\text { discomfort. Pain intensity was statistically superior in CTG } \\
\text { during the first week. }\end{array}$ & [21] \\
\hline $\begin{array}{c}\text { Maxillary Sinus } \\
\text { Augmentation } \\
\text { (Graft) }\end{array}$ & $10 / 11$ & $\begin{array}{l}\text { (1) PRF + Bio-Oss }{ }^{\circledR} \\
\text { (2) Bio-Oss }{ }^{\circledR}\end{array}$ & 6 & $\begin{array}{l}\text { Healing was uneventful for all patients. Both groups exhibited } \\
\text { an adequate amount and density of radiographic mineralized } \\
\text { tissue plus a similar composition, distribution, and } \\
\text { inflammation of histological structures. Intergroup differences } \\
\text { were non-significant. The percentage of newly formed bone } \\
\text { was about } 1.4 \text { times greater in the PRF group }(18.35 \pm 5.62 \% \text { vs. } \\
12.95 \pm 5.33 \% \text { of control). The percentage of residual bone } \\
\text { substitute material was about } 1.5 \text { times greater in the control } \\
\text { group ( } 28.54 \pm 12.01 \% \text { vs. } 19.16 \pm 6.89 \% \text { of LPRF). } \\
\text { The bone-to-bone substitute contact was } 21.45 \pm 14.57 \% \text { and } \\
18.75 \pm 5.39 \% \text { in the PRF and the control group, respectively. } \\
\text { Intergroup differences were non-significant. }\end{array}$ & [22] \\
\hline $\begin{array}{l}\text { Maxillary Sinus } \\
\text { Augmentation } \\
\text { (Membrane) }\end{array}$ & $6 / 12$ & $\begin{array}{l}\text { (1) PRF } \\
\text { (2) Bio-Gide }\end{array}$ & 5 & $\begin{array}{l}\text { Wound healing was uneventful for all patients. No soft tissue } \\
\text { in-growths were observed in both groups. Surfaces seemed } \\
\text { homogenous with visible bone-substitute material embedded } \\
\text { into newly-formed bone. The average amount of vital bone and } \\
\text { bone substitute were } 17.0 \% \text { and } 15.9 \% \text { in the PRF group. } \\
\text { Control group had } 17.2 \% \text { and } 17.3 \% \text {. No intergroup } \\
\text { comparisons were carried out. }\end{array}$ & [23] \\
\hline $\begin{array}{l}\text { Alveolar Socket } \\
\text { Preservation }\end{array}$ & $20 / 40$ & $\begin{array}{c}\text { (1) PRF } \\
\text { (2) Empty (blood clot) }\end{array}$ & 3 & $\begin{array}{l}\text { Soft tissue healing was significantly better in the PRF group vs. } \\
\text { the controls (Laundry, Turnbell and Howley Soft Tissue } \\
\text { Healing Index). Early bone formation/maturation was noticed } \\
\text { for the experimental sites vs. controls. Differences were } \\
\text { significant only at eight weeks post-extraction and favored the } \\
\text { PRF group. Higher bone density was noticed in the PRF group } \\
\text { vs. controls. Intergroup differences were non-significant. Mean } \\
\text { post-surgical pain (measured by Visual Analogue Scale (VAS) } \\
\text { score) was reduced in the PRF group vs. non PRF controls at } \\
\text { day 1. By day 7, no intergroup differences were noticed. }\end{array}$ & [24] \\
\hline
\end{tabular}




\subsection{PRFs in the Periodontal Intra-Bony Defects (IBDs) Treatment}

The regeneration of periodontal tissue is conventionally known as the generation of new cementum, alveolar bone, and a functional periodontal ligament on a tooth-supporting root surface that is previously diseased. Due to limited intrinsic regenerative potential, intra-bony defects (IBDs) are a common and challenging sequel of periodontal disease. Meta-analyses demonstrated that treatment with conservative open flap debridement produces an average clinical attachment (CAL) gain of $2.0 \mathrm{~mm}$ [25]. While about $1.5 \mathrm{~mm}$ may be attributed to newly formed bone, bone-fill does not implicate the regeneration of new attachment to the root [25]. In this context, PRFs appear promising for the regeneration of the whole periodontal attachment system (Figure 4A,B). Seven RCTs addressing the prospective application of PRFs periodontal therapy IBD have been found. Articles that have been found allowed for the following comparisons: (a) PRF/open flap surgery versus open flap surgery [9-11]; (b) PRF/Bio-Oss ${ }^{\circledR}$ constructs (Bio-Oss ${ }^{\circledR}$, Geistlich Pharma North America, Inc., Princeton, NJ, USA) versus PRF [12] and (c) PRF/DFDBA constructs versus DFDBA (demineralized freeze-dried bone allograft) [13] (d) PRF/inorganic bovine bone mineral (ABBM) versus ABBM alone [14] and (e) resorbable collagen membrane + PRF versus guidance tissue regeneration [15]. All of the patients who were included in those studies were periodontally stable and systemically healthy individuals who presented: a similar bilateral IBD of at least 5-mm probing depth located in vital asymptomatic teeth with no furcation involvement. Studies evaluating the addition of PRF to a conventional open flap procedure reported the biomaterial notably improving both the clinical and radiographic parameters of IBDs, after nine [9,11] and 12 months [10]. A significant improvement in probing depth (PD) decrement, CAL increase, post-treatment gingival margin stability [(GMS) less post-treatment gingival recession], bone defect fill, and percentage bone defect fill were noticed in all of the PRF-treated sites versus controls [9-11]. Interestingly, higher patient acceptance was also associated with the use of PRFs. This is most likely attributed to the accelerated wound healing and pain-inhibitory properties $[9,10]$. The presented PD reduction and CAL gain values were superior to previously-reported values in a meta-analysis performed for open flap surgery [25], suggesting the additional advantages of PRFs over the conventional approach. Treatment with PRF/particulate bone-graft substitutes (Bio-Oss ${ }^{\circledR}$ [12] and DFDBA [13]) provided additional statistically significant advantages regarding PD reduction, CAL gain, and bone defect fill versus graft substitutes after six months. Nonetheless, the absence of a "simultaneously-run" PRF-alone control renders it difficult to distinguish between the effects of PRFs and other potential variables in the study. Thus, while promising, additional studies are deemed essential in order to appropriately determine (quantifiably) the effectiveness and advantages of PRFs application over particulate bone-grafts use.

\subsection{PRFs in the Periodontal Furcation Defects (PFDs) Treatment}

From periodontitis, many molars result with furcation involvement, promoting higher rates of periodontal breakdown and poorer prognosis than single-rooted teeth [26]. Contemporary treatment options often include the use of regenerative materials and bone grafts; however, the introduction of PRFs seems promising for better therapeutic outcomes. In our analyses, one RCT addressing the therapeutic use of PRFs in PFDs was found [16]. The study compared PRF/open flap versus open flap debridgement alone in the therapy of grade-II mandibular discrepancies. Included patients were periodontally stable and systemically healthy, with similar bi-lateral grade II buccal furcation defects (at least $5 \mathrm{~mm}$ of probing depth and $\geq 3 \mathrm{~mm}$ of horizontal probing depth), in vital asymptomatic mandibular first molars.

PRF use significantly improved clinical and radiographic parameters of conventional open flap debridement. After nine months, the defect's complete clinical closure was successful in $66.7 \%$ of L-PRF-treated locations. Severity within residual defects was reduced in five out of six sites (degree I), whereas one defect remained in degree II. Significantly greater PD reduction, radiographic vertical defect fill, and CAL gain was reported on experimental sites versus controls. PRF use was also associated with a greater post-treatment GMS [16]. 


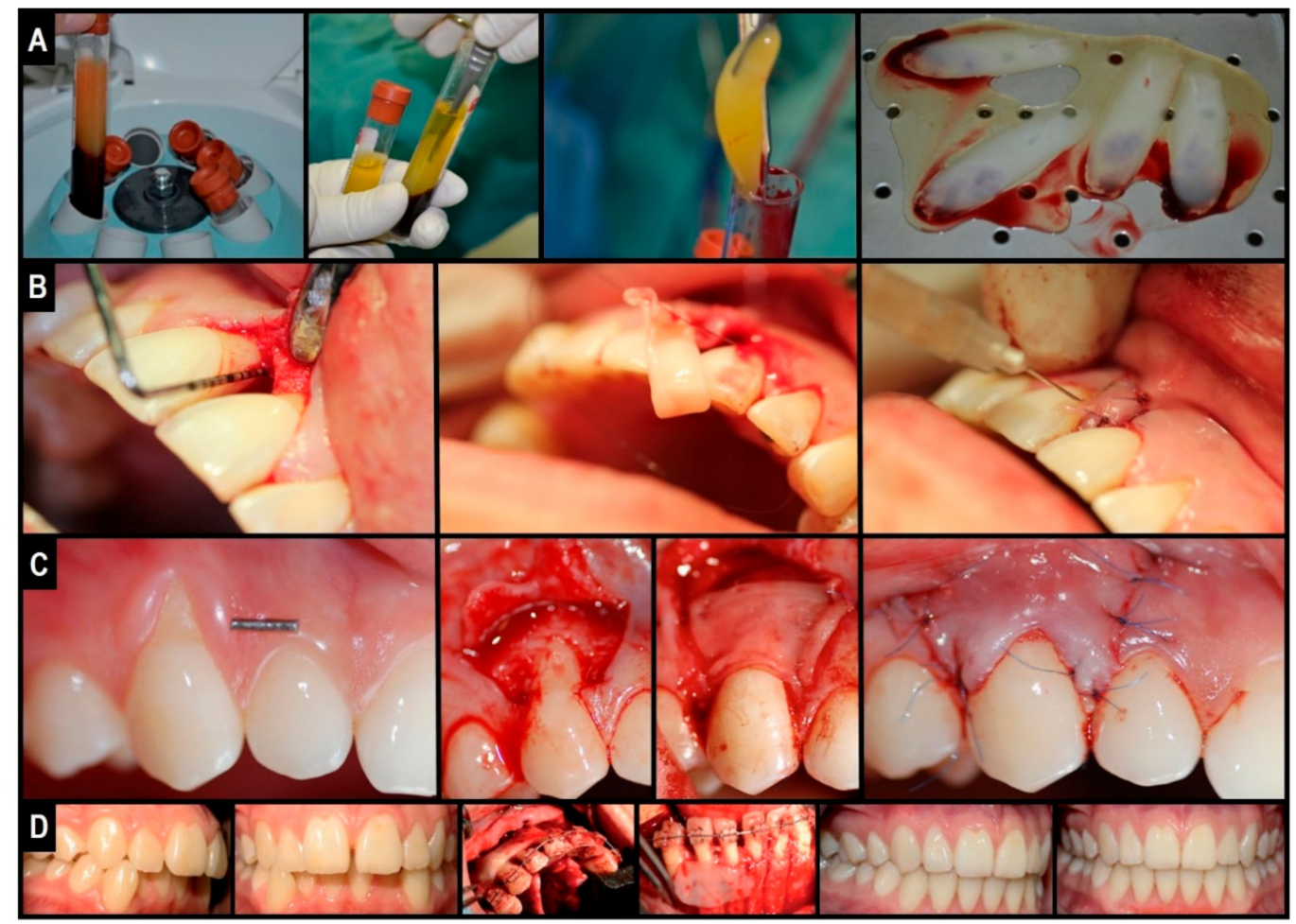

Figure 4. Clinical illustration of L-PRF application in oro-maxillo-facial surgery defect regeneration: natural guided tissue bio-engineering using L-PRF as a "bio-scaffold". (A) L-PRF membrane preparation; (B) clinical application in IBDs or for the treatment of periodontal intra-bony defects; (C) Clinical application under CAF or coronally advanced flaps in the treatment of gingival tissue recession; (D) clinical application in PAOO, or periodontally accelerated osteogenic orthodontics-an orthognathic procedure.

\subsection{Miller Class I and II Gingival Recession Treatment by PRFs}

Gingival recession is characterized by the root surface exposure caused by the gingival margin's apical migration. If left untreated, the condition may lead to other problems including: deficient esthetics, dentine hypersensitivity, and a higher risk of dental caries [27]. Available treatment options include the application of: (a) coronally-advanced flaps (CAF); (b) connective tissue grafts (CTG); and (c) sub-epithelial connective tissue grafts (SCTG). On their own, the aforementioned techniques have important limitations such as (a) unpredictable long-term root coverage (i.e., CAF decreases from $89 \%$ to $58.8 \%$ after six months); (b) limited gain of keratinized tissue width (KTW), which is important to prevent recurrence; and (c) adverse post-surgical effects such as pain/discomfort, swelling, flap necrosis, etc. [27]. In this review, in the context of dental care of gingival recessions, seven RCTs evaluating the appliance of PRFs were identified and included. The investigations allowed for the following comparisons: (a) PRF/CAF versus CAF [17,18]; (b) PRF/CAF versus EMD (enamel matrix derivate)/CAF [19]; (c) PRF/CAF versus CTG [21]; and (d) PRF/CAF versus SCTG [20]. Similar to previous RCTs, all of the patients included herein were periodontally stable and systemically healthy; they presented with: similar bi-lateral Miller Class I or II gingival recessions ( $\geq 2 \mathrm{~mm}$ depth) localized on vital teeth, without restorations. According to Padma et al., the addition of PRF to CAF improved both clinical outcomes and the post-treatment stability of CAF [17]. After six months, the authors reported (significantly) more recession depth (RD) reduction, CAL gain, and KTW increase in all of the PRF-treated sites versus controls. Interestingly, post-treatment GMS was also higher in the test group with $100 \%$ root coverage after six months versus $64.88 \%$ in controls [17]. However, in contrary with this RCT, Aroca et al. reported limited clinical benefits when using the PRF/CAF approach [18]. 
Herein, CAL gain and gingival tissue thickness (GTH) were the only benefiters of the combination; when comparing CAF-alone controls to the test group, significantly higher percentage root coverage, full root coverage, GMS, and recession width (RW) reduction were found in the first group [18]. Such "contradictory" results may be partially explained by deficient study design, which not only failed to adequately include blind examiners (leading to potential bias in favor of the "traditional" approach), but also included: multiple adjacent gingival recessions (with poorer prognosis than single/localized recessions); heavy smokers (in which healing response is usually altered); and the PRFs were stored in a $4{ }^{\circ} \mathrm{C}$ refrigerator until use (PRFs protocols often recommend immediate/fresh use). Indeed, emerging evidence states that growth factor release from PRFs initiates as early as $5 \mathrm{~min}$ from preparation (centrifugation step mainly). Hence, storage could have altered its properties and thereby diminished or deteriorated its clinical potential. When compared with other root coverage procedures (EMD/CAF, CTG, and SCTG), the PRF/CAF approach showed similar clinical outcomes regarding $\mathrm{RD}$ reduction, $\mathrm{CAL}$ gain, mean root coverage (\%), and complete root coverage (\%). The only exception was KTW increase, with both EMD/CAF and CTG controls showing higher KTW than PRF-treated groups [19-21]. Interestingly, all of the studies reported significantly faster healing and fewer complications (pain and discomfort) when PRF was used [19-21]. The findings are notable, especially when comparing with SCTG (the current "gold standard" technique for managing Miller Class I and II gingival recessions), indicating that PRF/CAF could be a safer and less invasive alternative to current grafting techniques, and a more cost-effective strategy or approach than EMD in the treatment of Miller Class I and II gingival recessions (Figure 4C).

\subsection{PRFs in Sinus Floor Augmentation}

The resorption of the upper jaw bone after tooth loss is a frequent problem faced in posterior maxillary implant placement due to the lack of required bone mass for anchorage. Common maxillary sinus augmentation techniques provide a solution via increasing the available bone height at the expense of sacrificing volume of the maxillary sinus [28]. Traditionally, autologous bone grafts and resorbable membranes are used to promote osteogenesis and avoid soft tissue in-growth into the surgical site. However, donor site morbidity and size restrictions, the latter resorption of the graft, and the high cost of membranes are the main disadvantages $[29,30]$. In this context, PRFs appear to provide a promising alternative overcoming such limitations. In this review, two RCTs evaluating the use of PRFs in lateral window sinus augmentation were found. Applications were performed either as: (a) grafting material (PRF/Bio-Oss ${ }^{\circledR}$ constructs versus Bio-Oss ${ }^{\circledR}$ ) [22] or (b) absorbable covering membrane for the lateral osteotomy window (PRF versus Geistlich Bio-Gide ${ }^{\circledR}$ ) [23]. In both studies, included subjects were systemically healthy adults with maxillary atrophy (defined as $<5 \mathrm{~mm}$ residual bone crest height measured in OPG/orthopantomogram). Smoking status was not assessed. The addition of PRF to Bio-Oss ${ }^{\circledR}$ bone substitute revealed neither advantages nor disadvantages over Bio-Oss ${ }^{\circledR}$-alone controls [22]. After six months, clinical and radiographic examinations revealed both groups exhibiting similar amounts and density of mineralized tissues, with no signs of material resorption. Histological evaluations also showed non-significant differences regarding: (a) newly generated bone percentage; (b) residual Bio-Oss ${ }^{\circledR}$ percentage; (c) bone-to-bone-substitute contact; and (d) post-treatment inflammatory reactions [22]. Regarding coverage of the lateral osteotomy sinus window, PRF use resulted in a comparable amount of residual bone substitute and vital bone formation (\%) when faced against Bio-Gide ${ }^{\circledR}$ controls (PRF: $17.0 \%$ and 15.9\%, Bio-Gide ${ }^{\circledR}: 17.2 \%$ and $17.3 \%$, differences are not statistically significant). Overall, despite a slightly superior to no coverage at all $(12.1 \%)$, it can be stated that results were similar to those reported using other conventional membranes (collagen: 17.6\%; e-PTFE (expanded polytetrafluoroethylene): 16.9\%) [23]. Within the presented limitations in both RCTs, evidence suggests that PRFs are safe, simple to use and handle, and a cost-effective alternative to traditional bone grafts and absorbable membranes for low-income patients pursuing maxillary sinus augmentation procedures. 


\subsection{PRFs in Alveolar Ridge Preservation}

Post-extraction changes in alveolar bone compromise prosthodontic rehabilitation with fixed, removable and/or implant-supported prosthesis. Alveolar ridge preservation (ARP) is a technique that involves the application of grafting and barrier materials in order to significantly reduce post-extraction bone loss [31]. It has been demonstrated that PRFs are able to accelerate/enhance bone repair [32,33], promote fibroblast proliferation [3,33], and increase vascularity [24], thereby potentially favoring the post-extraction healing process and the ARP approach. Yet, a single RCT evaluating the use of PRF in ARP was identified, according to the inclusion criteria set herein [34]. This sole study compared the application of PRF versus natural blood clots in post-extraction sockets of third molars. Patients were systemically healthy and non-smoking adults requiring bi-lateral mandibular third molar removal. The use of PRF significantly improved post-extraction soft tissue healing after seven days [34]. Early and significantly higher radiographic bone formation/maturation was noticed in the PRF-treated sites versus controls at eight weeks. By 12 weeks, intergroup differences were non-significant. Radiographic bone density (measured by gray scale value) at 12 weeks increased in the biomaterial group compared with the controls; nonetheless, the differences were not significant [34]. Similar to other studies, PRF reduced early post-surgical pain (VAS scale: Visual Analogue Scale) on day 1 ; however, intergroup differences were not significant by day 7 [34].

\subsection{Clinical Expertise with L-PRF in Periodontally Accelerated Osteogenic Orthodontics}

In the pilot phase of our own prospective observational study [33], including 11 patients into the cohort (with informed consent) receiving a Wilcko's modified PAOO (periodontally accelerated osteogenic orthodontics-method that combines orthodontic efforts with corticotomy and grafting of alveolar bone plates allowing faster tooth movement, which is considered a rather new surgical practice) approach alongside L-PRF (added as covering membrane and into the graft), accelerated wound healing without evident signs of infection or adverse reactions (Figure 4D). For 10 days, post-operative pain, inflammation, and infection were recorded, while the follow-up of the overall orthodontic treatment and post-treatment stability lasted two years. In our data analysis, post-surgical pain and immediate inflammation after surgery were found to be either "mild", with $45.5 \%$ for the first one and $89.9 \%$ for the second, or "moderate", with $54.5 \%$ and $9.1 \%$, respectively; and the majority of patients suffered either "mild" or no inflammation $(72.7 \%$ and $9.1 \%$, respectively) on day 4 , where settlement was marked to begin. Interestingly, by day 8 , a complete resolution was achieved in all patients; the average orthodontic treatment time was calculated at 9.3 months, and all of the cases were stable throughout. Thus, we concluded that combining L-PRF with traditional bone grafts (L-PRF plug or block) possibly stimulates the healing of the wound and diminishes pain after surgery, inflammation, and infection with no interference in the movement of the tooth and/or stability after orthodontic treatment over a two-year observational extent of time; thereby, the demand for analgesics and anti-inflammatory medications is alleviated [33]. Our recommended preparation protocol for reproducible and clinically usable and malleable L-PRF clots and membranes is defined in Table 2. 
Table 2. Author's recommendations for L-PRF preparation.

\begin{tabular}{l}
\hline Recommended Preparation Protocol for Clinically-fit L-PRF (Clots, Plugs, Blocks and Membranes) \\
Collect 5-9 mL whole venous blood sample into 2-3 sterile $6 \mathrm{~mL}$ \\
glass-coated plastic vacutainer tubes (without anti-coagulant \\
-clot formation). \\
\hline Centrifuge immediately for 10-12 min at 2700-3000 rpm \\
(revolutions per minute) using any high-quality table-top centrifuge. \\
\hline Fibrinogen $\rightarrow$ Fibrin. Typically, 3 distinct compartments should be \\
evident in each tube. UPPER Portion: straw-colored acellular \\
plasma (PPP); MIDDLE Portion: yellowish fibrin clot (FC); and \\
LOWER Fraction: red-colored corpuscles of red blood cells (RBCs). \\
Quickly remove the upper layer to reveal and collect the middle \\
portion; around 2 mm below the lower dividing line. Timing is \\
critical to obtain bioactive L-PRFs charged with serum and platelets. \\
This clot can then be used directly, either (a) as filling material; (b) \\
mixed with bone grafting materials(s) - plugs and blocks; and/or (c) \\
compressed (using the surgical box to prevent damage and to collect \\
fibrin surgical glue in reservoir) into a strong and resilient \\
clinically-usable membrane. For injectable PRF or iPRF (a more \\
liquid or flowable formulation), centrigue tube again for 3-4 more \\
minutes and collect top 1 mL layer using a syringe suitable for \\
immediate injection into the intended application site. Mixing with \\
other biomaterials is feasible as well. Note: slower centrifugation \\
(less than 1500 rpm)for less time period (around 6-8 min) will result \\
in a preparation with higher white blood cell count, commonly \\
termed Advanced PRF or A-PRF suitable for defects requiring more \\
vascularization (5 min needed to induce fibrin clot formation). \\
\hline
\end{tabular}

\section{Conclusions and Closing Remarks}

Tissue regeneration and anatomical reconstruction and repair in defects of the oromaxillofacial complex have been consistently a critical and controversial concern. Both quality and quantity of the regenerated tissues are important to consider, aesthetically and functionally. Practically, the surgeon is faced with an ample collection of regenerative techniques and materials to choose from. How can one select the "ideal" or "best fit" strategy and procedure to meet the most favorable clinical outcome? Evidence-based studies? Level of scientific evidence? This review, to the best of our knowledge, is the first concerning randomized controlled clinical trials on PRFs' use and application in specific oral and maxillofacial surgery procedures, bridging the gap between the clinical and the materials expert. While the available literature is found to be highly limited, PRFs can still be indicated as an innovative tool for contemporary oromaxillofacial tissue regeneration and bioengineering. Indeed, the existing evidence suggests that PRFs improve early wound healing and promote post-surgical bone formation/maturation. However, it is noteworthy that a clearer consensus seems to be present regarding its significant beneficial impact on post-surgical pain and discomfort control, regardless of the type of procedure. Unlike its predecessors, new PRF preparations tend to function more as biologically active biomaterials and scaffolds for autologous cell, growth factors, and cytokines delivery. Thus, PRFs should be considered a "living tissue" preparation for natural guided tissue regeneration, and not simply a "growth factor-rich" surgical adjuvant. Yet, it is safe to say that this remains an unexplored territory in dental biomaterial (Dental BioEngineering) research in general.

Currently, our group is investigating the potential of (a) incorporating mesenchymal stem cells derived from orodental routes and (b) core-shell nanoparticles loaded with growth factor(s) and incorporated or embedded within the PRFs as "super" or "smart" bio-scaffolds to further promote soft tissue healing, bone generation, treatment time, post-surgical stability, and outcome predictability, in advanced oromaxillofacial surgical procedures such as periodontally accelerated osteogenic orthodontics (PAOO) and mental genioplasty [35]. Further, in the context of invasive surgical procedures such as third molar extraction and cysts resections, the ultimate objective of our research focuses on the potential of PRFs in decreasing the need for prescription drugs. Finally, 
we are vigorously working on characterizing the rheological properties and biological variations of PRFs, alongside partnering up with nurses, physicians, and dentists to standardize the preparation protocol for use in other therapeutic indications, including orthopedics, in an effort to address and resolve the underlying challenges and limitations outlined earlier herein that are slackening their clinical translation.

Funding: Generous funding and operating grants supported this work by providing to the BioMAT'X Research Group, part of CIIB (Centro de Investigación e Innovación Biomédica), through the Faculty of Dentistry and PMI (Plan de Mejoramiento Institucional en Innovación I+D+i), Department for Research, Development and Innovation, Universidad de los Andes, Santiago de Chile. The corresponding author (Z.S.H.) acknowledges supplementary operating funding provided from CONICYT-FONDEF Chile under awarded project/grant (national) \#ID16I10366 (2016-2019) and Fondo de Ayuda a la Investigacion FAI-Universidad de los Andes No. INV-IN-2015-101 (2015-2019). This work is related with the ongoing R\&D\&I project nanoL-PRF at BioMAT'X.

Acknowledgments: Nelson Pinto for providing the SEM micrographs (lower row in Figure 2) and Dra. Macarena Llompart for providing the clinical photographs for L-PRF use in periodontics (Figure $4 \mathrm{~B}, \mathrm{C}$ ). The corresponding authors wishes to dedicate a special thanks to Maryam Tabrizian for the kind invitation to contribute to this Special Issue, celebrating the 10th Anniversary of "Materials" journal and her 60th birthday.

Conflicts of Interest: The authors of this review article declare having no conflict of interest of any form or nature with any platelet concentrate product, protocol, technique or company.

\section{References}

1. Habibovic, P.; de Groot, K. Osteoinductive biomaterials-Properties and relevance in bone repair. J. Tissue Eng. Regen. Med. 2007, 1, 25-32. [CrossRef] [PubMed]

2. Haidar, Z.S. NanoDentistry: Perspectives on the Role of NanoBiotechnology in Biomaterials, Pharmaceutics and BioDental Tissue Engineering. EC Dent. Sci. 2015, 3, 506-507.

3. Dohan, D.M.; Choukroun, J.; Diss, A.; Dohan, S.L.; Dohan, A.J.J.; Mouhyi, J.; Gogly, B. Platelet-rich fibrin (PRF): A second-generation platelet concentrate. Part II: Platelet-related biologic features. Oral Surg. Oral Med. Oral Pathol. Oral Radiol. 2006, 101, e45-e50. [CrossRef] [PubMed]

4. Del Corso, M.; Vervelle, A.; Simonpieri, A.; Jimbo, R.; Inchingolo, F.; Sammartino, G.; Dohan Ehrenfest, D.M. Current knowledge and perspectives for the use of platelet-rich plasma (PRP) and platelet-rich fibrin (PRF) in oral and maxillofacial surgery part 1: Periodontal and dentoalveolar surgery. Curr. Pharm. Biotechnol. 2012, 13, 1207-1230. [CrossRef] [PubMed]

5. Dohan Ehrenfest, D.M.; Rasmusson, L.; Albrektsson, T. Classification of platelet concentrates: From pure platelet-rich plasma (P-PRP) to leucocyte- and platelet-rich fibrin (L-PRF). Trends Biotechnol. 2009, 27, $158-167$. [CrossRef] [PubMed]

6. Simonpieri, A.; Del Corso, M.; Vervelle, A.; Jimbo, R.; Inchingolo, F.; Sammartino, G.; Dohan Ehrenfest, D.M. Current knowledge and perspectives for the use of platelet-rich plasma (PRP) and platelet-rich fibrin (PRF) in oral and maxillofacial surgery part 2: Bone graft, implant and reconstructive surgery. Curr. Pharm. Biotechnol. 2012, 13, 1231-1256. [CrossRef] [PubMed]

7. Dohan, D.M.; Choukroun, J.; Diss, A.; Dohan, S.L.; Dohan, A.J.J.; Mouhyi, J.; Gogly, B. Platelet-rich fibrin (PRF): A second-generation platelet concentrate. Part III: Leucocyte activation: A new feature for platelet concentrates? Oral Surg. Oral Med. Oral Pathol. Oral Radiol. 2006, 101, e51-e55. [CrossRef]

8. Bielecki, T.; Dohan Ehrenfest, D.M.; Everts, P.A.; Wiczkowski, A. The role of leukocytes from L-PRP/L-PRF in wound healing and immune defense: New perspectives. Curr. Pharm. Biotechnol. 2012, 13, 1153-1162. [CrossRef] [PubMed]

9. Thorat, M.; Pradeep, A.R.; Pallavi, B. Clinical effect of autologous platelet-rich fibrin in the treatment of intra-bony defects: A controlled clinical trial: Platelet-rich fibrin and periodontal regeneration. J. Clin. Periodontol. 2011, 38, 925-932. [CrossRef] [PubMed]

10. Rosamma Joseph, V.; Raghunath, A.; Sharma, N. Clinical effectiveness of autologous platelet rich fibrin in the management of infrabony periodontal defects. Singap. Dent. J. 2012, 33. [CrossRef] [PubMed]

11. Sharma, A.; Pradeep, A.R. Treatment of 3-wall intrabony defects in patients with chronic periodontitis with autologous platelet-rich fibrin: A randomized controlled clinical trial. J. Periodontol. 2011, 82, 1705-1712. [CrossRef] [PubMed] 
12. Lekovic, V.; Milinkovic, I.; Aleksic, Z.; Jankovic, S.; Stankovic, P.; Kenney, E.B.; Camargo, P.M. Platelet-rich fibrin and bovine porous bone mineral vs. platelet-rich fibrin in the treatment of intrabony periodontal defects: Xenograft and platelet-rich fibrin in intrabony defects. J. Periodontal Res. 2012, 47, 409-417. [CrossRef] [PubMed]

13. Bansal, C.; Bharti, V. Evaluation of efficacy of autologous platelet-rich fibrin with demineralized-freeze dried bone allograft in the treatment of periodontal intrabony defects. J. Indian Soc. Periodontol. 2013, 17, 361-366. [CrossRef] [PubMed]

14. Sezgin, Y.; Uraz, A.; Taner, I.L.; Çulhaoglu, R. Effects of platelet-rich fibrin on healing of intra-bony defects treated with anorganic bovine bone mineral. Braz. Oral Res. 2017, 31, e15. [CrossRef] [PubMed]

15. Panda, S.; Sankari, M.; Satpathy, A.; Jayakumar, D.; Mozzati, M.; Mortellaro, C.; Gallesio, G.; Taschieri, S.; Del Fabbro, M. Adjunctive Effect of Autologus Platelet-Rich Fibrin to Barrier Membrane in the Treatment of Periodontal Intrabony Defects. J. Craniofac. Surg. 2016, 27, 691-696. [CrossRef] [PubMed]

16. Sharma, A.; Pradeep, A.R. Autologous platelet-rich fibrin in the treatment of mandibular degree II furcation defects: A randomized clinical trial. J. Periodontol. 2011, 82, 1396-1403. [CrossRef] [PubMed]

17. Padma, R.; Shilpa, A.; Kumar, P.A.; Nagasri, M.; Kumar, C.; Sreedhar, A. A split mouth randomized controlled study to evaluate the adjunctive effect of platelet-rich fibrin to coronally advanced flap in Miller's class-I and II recession defects. J. Indian Soc. Periodontol. 2013, 17, 631-636. [CrossRef] [PubMed]

18. Aroca, S.; Keglevich, T.; Barbieri, B.; Gera, I.; Etienne, D. Clinical evaluation of a modified coronally advanced flap alone or in combination with a platelet-rich fibrin membrane for the treatment of adjacent multiple gingival recessions: A 6-month study. J. Periodontol. 2009, 80, 244-252. [CrossRef] [PubMed]

19. Jankovic, S.; Aleksic, Z.; Milinkovic, I.; Dimitrijevic, B. The coronally advanced flap in combination with platelet-rich fibrin (PRF) and enamel matrix derivative in the treatment of gingival recession: A comparative study. Eur. J. Esthet. Dent. 2010, 5, 260-273. [PubMed]

20. Eren, G.; Atilla, G. Platelet-rich fibrin in the treatment of localized gingival recessions: A split-mouth randomized clinical trial. Clin. Oral Investig. 2014, 18, 1941-1948. [CrossRef] [PubMed]

21. Jankovic, S.; Aleksic, Z.; Klokkevold, P.; Lekovic, V.; Dimitrijevic, B.; Kenney, E.B.; Camargo, P. Use of platelet-rich fibrin membrane following treatment of gingival recession: A randomized clinical trial. Int. J. Periodontics Restor. Dent. 2012, 32, e41-e50.

22. Zhang, Y.; Tangl, S.; Huber, C.D.; Lin, Y.; Qiu, L.; Rausch-Fan, X. Effects of Choukroun's platelet-rich fibrin on bone regeneration in combination with deproteinized bovine bone mineral in maxillary sinus augmentation: A histological and histomorphometric study. J. Craniomaxillofac. Surg. 2012, 40, 321-328. [CrossRef] [PubMed]

23. Gassling, V.; Purcz, N.; Braesen, J.H.; Will, M.; Gierloff, M.; Behrens, E.; Açil, Y.; Wiltfang, J. Comparison of two different absorbable membranes for the coverage of lateral osteotomy sites in maxillary sinus augmentation: A preliminary study. J. Craniomaxillofac. Surg. 2013, 41, 76-82. [CrossRef] [PubMed]

24. Chen, Y.; Niu, Z.; Xue, Y.; Yuan, F.; Fu, Y.; Bai, N. Improvement in the repair of defects in maxillofacial soft tissue in irradiated minipigs by a mixture of adipose-derived stem cells and platelet-rich fibrin. Br. J. Oral Maxillofac. Surg. 2014, 52, 740-745. [CrossRef] [PubMed]

25. Lang, N.P. Focus on intrabony defects-Conservative therapy. Periodontol. 2000 2000, 22, 51-58. [CrossRef] [PubMed]

26. Goldman, M.J.; Ross, I.F.; Goteiner, D. Effect of periodontal therapy on patients maintained for 15 years or longer. A retrospective study. J. Periodontol. 1986, 57, 347-353. [CrossRef] [PubMed]

27. Cortellini, P.; Prato, P.G. Coronally advanced flap and combination therapy for root coverage. Clinical strategies based on scientific evidence and clinical experience. Periodontol. 2000 2012, 59, 158-184. [CrossRef] [PubMed]

28. Boyne, P.J.; James, R.A. Grafting of the maxillary sinus floor with autogenous marrow and bone. J. Oral Surg. 1980, 38, 613-616. [PubMed]

29. Cordaro, L. Bilateral simultaneous augmentation of the maxillary sinus floor with particulated mandible. Report of a technique and preliminary results. Clin. Oral Implants Res. 2003, 14, 201-206. [CrossRef] [PubMed]

30. Van den Bergh, J.P.; ten Bruggenkate, C.M.; Krekeler, G.; Tuinzing, D.B. Sinusfloor elevation and grafting with autogenous iliac crest bone. Clin. Oral Implant. Res. 1998, 9, 429-435. [CrossRef] 
31. Hämmerle, C.H.F.; Araújo, M.G.; Simion, M.; Osteology Consensus Group 2011. Evidence-based knowledge on the biology and treatment of extraction sockets. Clin. Oral Implant. Res. 2012, 23, 80-82. [CrossRef]

32. Pripatnanont, P.; Nuntanaranont, T.; Vongvatcharanon, S.; Phurisat, K. The primacy of platelet-rich fibrin on bone regeneration of various grafts in rabbit's calvarial defects. J. Craniomaxillofac. Surg. 2013, 41, e191-e200. [CrossRef] [PubMed]

33. Muñoz, F.; Jiménez, C.; Espinoza, D.; Vervelle, A.; Beugnet, J.; Haidar, Z. Use of leukocyte and platelet-rich fibrin (L-PRF) in periodontally accelerated osteogenic orthodontics (PAOO): Clinical effects on edema and pain. J. Clin. Exp. Dent. 2016, 8, e119-e124. [CrossRef] [PubMed]

34. Singh, A.; Kohli, M.; Gupta, N. Platelet Rich Fibrin: A Novel Approach for Osseous Regeneration. J. Maxillofac. Oral. Surg. 2012, 11, 430-434. [CrossRef] [PubMed]

35. Muñoz, F.; Haidar, Z. L-PRF for Use in Oro-Maxillo-Facial Surgeries: What Do We Know? J. Oral Res. 2018, 7 , 88-90. [CrossRef]

(C) 2018 by the authors. Licensee MDPI, Basel, Switzerland. This article is an open access article distributed under the terms and conditions of the Creative Commons Attribution (CC BY) license (http://creativecommons.org/licenses/by/4.0/). 